\title{
BIOTA Southern Africa Biodiversity Observatories Vegetation Database
}

\author{
Gerhard Muche, Ute Schmiedel \& Norbert Jürgens
}

\begin{abstract}
The BIOTA Southern Africa Biodiversity Observatories Vegetation Database (AF-00-003) hosts the project-related data on spatial patterns and time series of biodiversity in southern Africa. Along a 2,000 km long transect, from the northern border of Namibia to the Cape of Good Hope, the plant diversity has been monitored on 37 Biodiversity Observatories for up to ten years (20012010). The design of the Observatories enables the observation of vegetation in nested, permanent plots where standardized measurements can be repeated. Information on species occurrence, cover and abundance has been recorded annually and stored in a database. These vegetation observations form a part of the interdisciplinary approach of BIOTA Southern Africa which assesses and monitors different organisms. In this paper, we describe how the vegetation data of the biodiversity monitoring project BIOTA Southern Africa, are managed. More than 400,000 species observations were recorded and stored in a database, covering a time-series of up to ten years. The Biodiversity Observatories are situated in along a major rainfall gradient, cover six biomes and are subject to different land use. The vegetation monitoring is on-going. The empirical data are a valuable source of information for various research questions ranging from testing theories on patterns, drivers of biodiversity at different spatial scales to studies on changes in biodiversity in space and time. The BIOTA Southern Africa Biodiversity Observatories Vegetation Database is currently explored to answer the following research questions: How many plant species exist at different scale levels? How does plant species composition change over time in relation to seasonal fluctuations, long-term climate change, environmental changes and human influences?
\end{abstract}

Keywords: climate change; ecoinformatics; long-term observation site; nested plot; permanent plot; relevé; species abundance; species cover; species richness; time series.

\begin{abstract}
Abbreviations: BIOTA AFRICA = Biodiversity Monitoring Transect Analysis in Africa; BOL = Bolus Herbarium, University of Cape Town, Rondebosch, South Africa; FAO SOTER = Global and National Soil and Terrain Digital Databases of the Food and Agriculture Organization of the United Nations; HBG = Herbarium Hamburgense, University of Hamburg, Germany; KMG = McGregor Museum Kimberley, South Africa; NBG = Compton Herbarium, Kirstenbosch, South Africa; NBRI = National Botanical Research Institute of Namibia; WIND = National Herbarium of Namibia, Windhoek, Namibia.
\end{abstract}

Received: 6 November 2010 - Accepted: 26 February 2012 - Co-ordinating Editor: Milan Chytrý.

\section{Introduction}

Southern Africa is renowned for its exceptional biological diversity (Huntley 1989, Davis et al. 1994, Cowling et al. 1994). It contains two of the 25 global biodiversity hotspots as identified by Myers et al. (2000), of which the Succulent Karoo is situated in an arid environment. This high biodiversity in the arid part of southern Africa has been partly interpreted as being the result of the climatic conditions during the last 5 million years (Jürgens 1997, Klak et al. 2004), and partly as being due to very long continuous speciation within the Cape Region (Linder 2003). The exceptional habitat diversity is driven by biotic (bioturbation, herbivory) and abiotic environmental drivers such as topography, soil, and rain- fall patterns (Cowling et al. 1994, Medinski et al. 2010, Petersen et al. 2010, Schmiedel et al. 2010b). These are discussed as they are seen as being important drivers. Climate change (Thuiller et al. 2006, Midgley et al. 2007, Musil et al. 2009) and unsustainable land use practices (Hoffman \& Ashwell 2001, Biggs et al. 2008) have been identified as the main threat to the southern African biological diversity.

However, very little is understood about the processes of how the environmental changes will affect the natural environment. While human beings have very long-standing experiences of the impact of land use on species composition as a result of a wealth of practical experiences and academic research results, climate change is an unparalleled experience for humankind. Thus its environmental impact is much less predictable. The accuracy of trends for future species losses depicted by climate change projections (Thomas et al. 2004; MacClean et al. 2006; van Vuuren et al. 2006; Sommer et al. 2010) strongly depends on the availability and quality of empirical baseline data on local patterns of biodiversity, their dynamics and interactions within communities, habitats and climate. However, these data are particularly scarce (Scholes et al. 2008). Therefore there is an urgent need for evidence-based information on the current state of biodiversity, its rate, quality and direction of change for the models as well as management, adaptation and mitigation decisions (Araújo et al. 2005). 


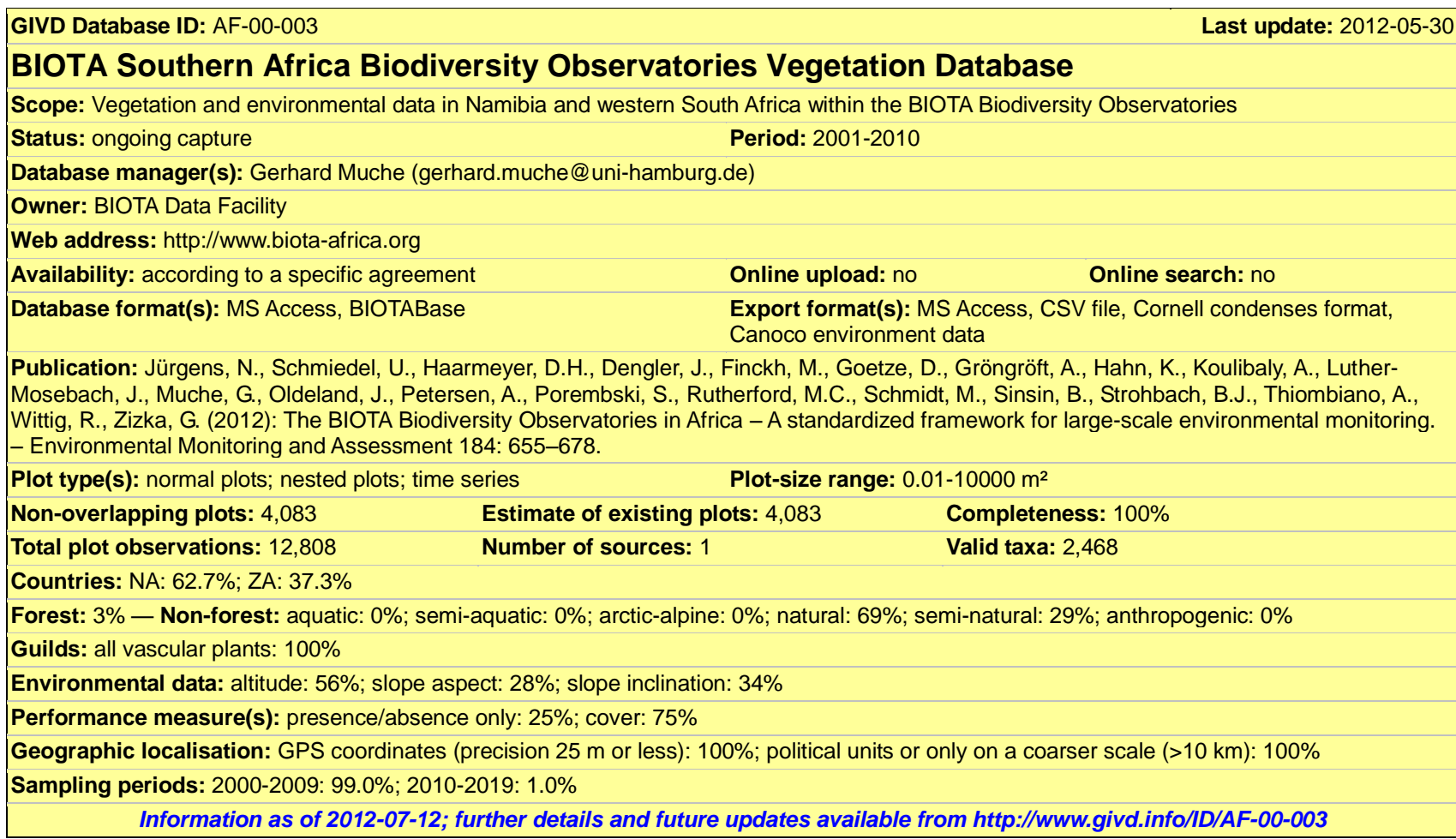

One of the main research aims of the international biodiversity research initiative, BIOTA Southern Africa, is to assess the current state of biodiversity in southern Africa, monitor and analyse changes that occur due to land use and climate change (Krug et al. 2006, Jürgens et al. 2010a). To accomplish this goal, in 2001, BIOTA Southern Africa established a series of standardised long-term biodiversity monitoring sites, the Biodiversity Observatories of southern Africa (Namibia and South Africa, Schmiedel et al. 2010b). The Biodiversity Observatories in southern Africa are located along a long NorthSouth transect and two shorter West-East transects in Namibia, thus covering major climatic gradients, and the six major biomes of the western part of southern Africa (i.e. Woodland Savanna, Thornbush Savanna, Nama Karoo, Namib Desert, Succulent Karoo, and Fynbos, see Fig. 1). Several Biodiversity Observatories are arranged as pairs to represent the different land tenure or management types typical for the region (e.g. commercial or communal rangeland farming, conservation). The principles of site selection and spatial layout of the Biodiversity Observatories are described by Jürgens et al. (2010b, 2012).

The project forms part of a standardised biodiversity monitoring network (BIOTA AFRICA), which involves biodiversity monitoring and research along major environmental gradients in Northern Africa
(Morocco), West Africa (Benin, Burkina Faso, Cote d'Ivoire), and East Africa (Kenya, Uganda) (Jürgens et al. 2012, see also http://www.biota-africa.org). The Biodiversity Observatories provide the infrastructure for interdisciplinary biodiversity monitoring and research. In southern Africa the multidisciplinary, interrelated long-term data on biodiversity patterns (e.g. soils, biological soil crusts, lichens, vascular plant vegetation, weather and land use) provides the basis for the analyses of patterns, processes and their drivers in space and time (e.g. Büdel et al. 2009, Medinski et al. 2010, Petersen 2008, Schmiedel et al. 2010b).

Monitoring data of the BIOTA Southern Africa Observatories on the composition and richness of vascular plants species, which are the main primary producers and one of the first macroscopic indicators of environmental changes, represents one of the most comprehensive long-term monitoring datasets in southern Africa (Haarmeyer et al. 2010, Jürgens et al. 2012). In this paper, the structure, focus and content of the BIOTA Southern Africa Biodiversity Observatories Vegetation Database is outlined, the relationships to taxonomy and the handling of specimens presented and the value of these data for applied biodiversity research discussed.

\section{Vegetation monitoring data of the BIOTA Biodiversity Obser- vatories}

Each of the BIOTA Biodiversity Observatories encompasses an area of $1 \mathrm{~km}^{2}$ $(1,000 \mathrm{~m} \times 1,000 \mathrm{~m})$ with the boundaries oriented along cardinal directions. This 1 $\mathrm{km}^{2}$ area is divided into 100 1-ha plots $(100 \mathrm{~m} \times 100 \mathrm{~m})$. All corner points are georeferenced and visually marked with metal poles. The hectare plots represent the largest replicated sampling unit within the BIOTA Observatory (Jürgens et al. 2010b, 2011). These plots are classified according to habitat types and subjected to a habitat-stratified ranking (for further details on the ranking procedure, see Jürgens et al. 2010a: 13). North of the centre of the hectare plot a $10 \mathrm{~m} \times 10 \mathrm{~m}$ plot is laid out and nested inside a $20 \mathrm{~m} \times 50 \mathrm{~m}$ plot (Fig. 2). The 100- $\mathrm{m}^{2}$ and $1,000-\mathrm{m}^{2}$ plots within the 20 highest ranked hectare plots are monitored annually during the peak of the growing season.

On the $100 \mathrm{~m}^{2}$ plots, all vascular plant species are recorded for their abundance and the projected cover values in percentages (down to $0.01 \%$ ). On the $1,000 \mathrm{~m}^{2}$ plots, vascular plant species are recorded for their projected cover values and on the hectare plot $\left(10,000 \mathrm{~m}^{2}\right)$ only for occurrence. For the latter, it is accepted that where the Biodiversity Observatories have very dense and species-rich vegetation the species inventories for the hectare 
plots are incomplete (Dengler et al. 2010). According to Peters (2010) during a very good season with a comparably high species richness and density of vegetation up to $40 \%$ of the species were not recorded on the 1 hectare plot; these were mainly rare, low-growing, and/or annual forbs or graminoids. The BIOTA Biodiversity Observatories are long-term monitoring sites and thus revisited at regular intervals. Some properties of a plot (e.g. GPS coordinates, altitude, slope inclination and aspect, topography, landscape, geology) will not change within a time span relevant to human beings and they were therefore recorded only once at the beginning of the long-term monitoring.

Other potential drivers of plant species composition (such as land use type, visible land use impact, soil surface features etc.) are subject to changes over time and are therefore monitored in the same intervals as vegetation. Weather data (i.e. rainfall, air temperature, wind speed and direction, leaf wetness, relative humidity of air, and solar radiation) are recorded hourly by automatic weather stations in the vicinity of the Biodiversity Observatories. Weather data are available online at the BIOTA AFRICA website http://www.biota-africa.org/weather_start _ba.php for the period from 2001 to 2010 and http://www.biota-africa.org/weather/ for data since 2010. All data recorded either once or regularly at the Biodiversity Observatories are standardised by using a standard data sheet. In addition, each $100 \mathrm{~m}^{2}$ and $1,000 \mathrm{~m}^{2}$ plot is photographically documented with several exposures in a standardised way (see Plate).

The structure of the BIOTA Southern Africa Biodiversity Observatories Vegetation Database reflects the different types of data assessed on the monitoring plots. A relevé is a record of the species composition with structural and environmental information at a defined location and time. Therefore records of the species composition on permanent plots at different times have variable and non-variable parts. The non-variable plot information, as well as the variable data on abiotic habitat, land use characteristics, and the repeated vegetation relevés are stored in different data tables and are displayed with different views of a graphical user interface.

The non-variable plot descriptors are displayed in the Plots view. They reflect a more general geographical and administrative information (the General data), as well as the non-variable site descriptors at different spatial scales. These scales are:
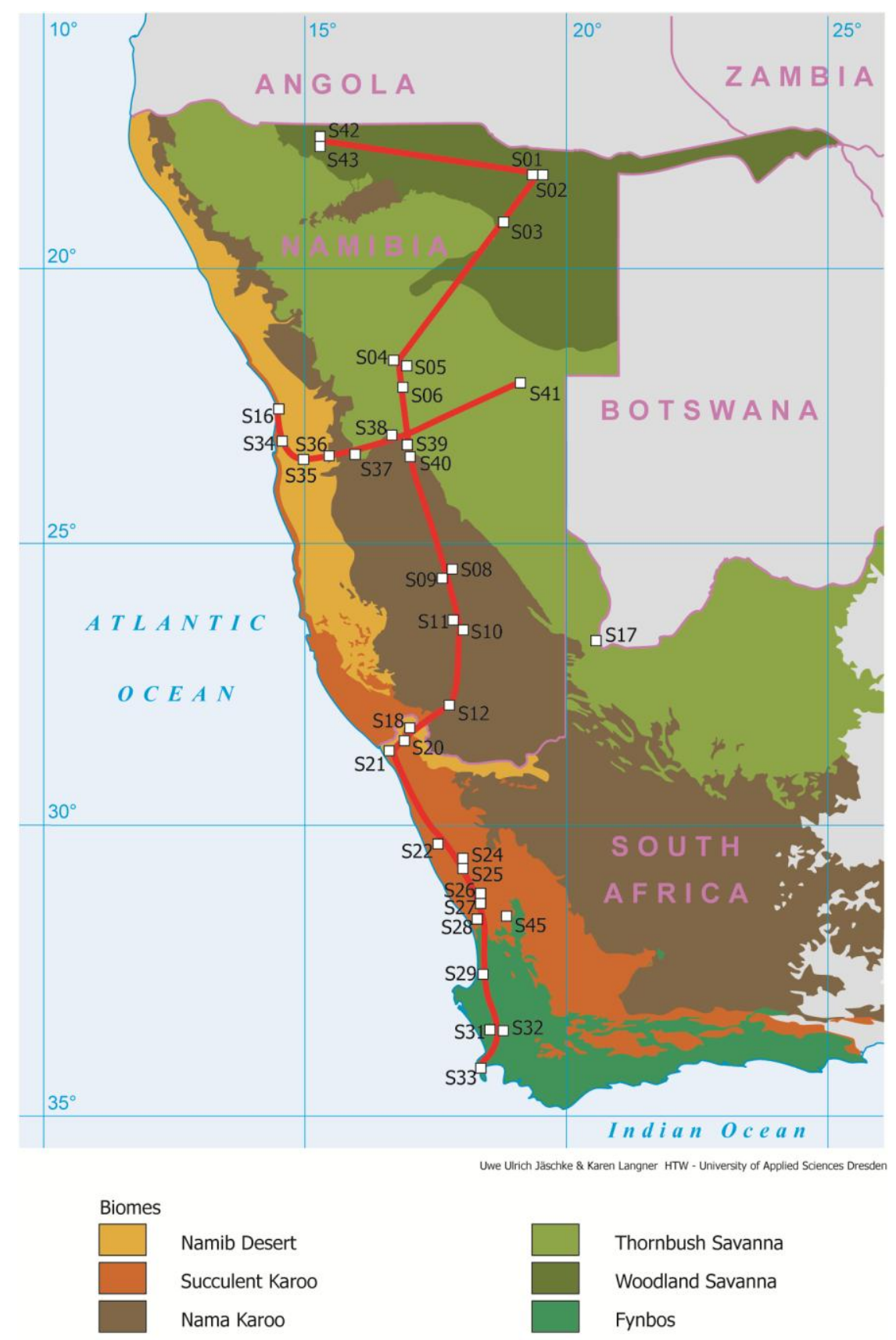

Transect

口 S32 BIOTA Observatory $\quad 0 \quad 250 \quad 500 \mathrm{~km}$

Fig. 1: BIOTA Biodiversity Observatories of BIOTA Southern Africa within the biomes of southern Africa, compiled according to Mucina \& Rutherford (2006), Mendelsohn et al. (2002) and Jürgens (unpublished data) (Map drawn by Uwe U. Jäschke \& K. Langner, first published by Schmiedel et al. 2010a).

a) SOTER data, which describe the broader landscape $\left(25 \mathrm{~km}^{2}\right)$ for each of the plots; b) the medium-scale Landscape description refers to the landscape type (e.g. coastal dunes) and the particular landscape element (e.g. dune slack) where the plot is situated; and finally c) the de- scription of the Local topography of the plot itself which provides information on the plot's position on the slope, slope inclination or aspect related to the cardinal directions. 
a

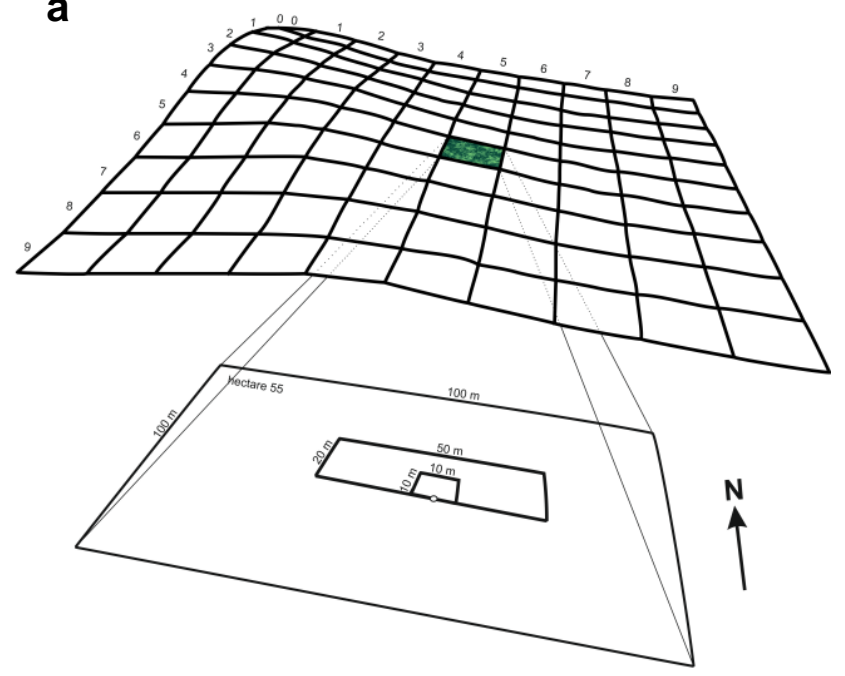

b

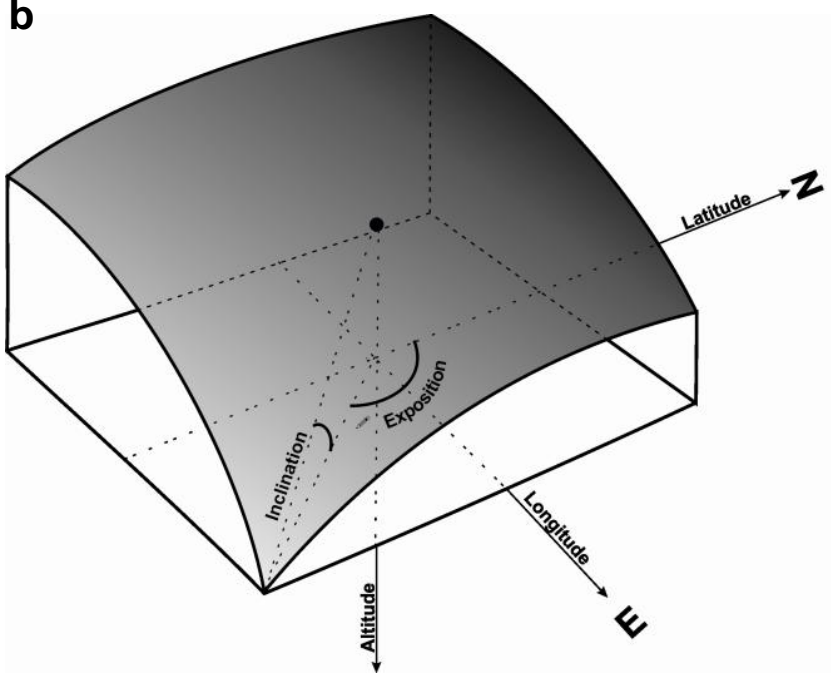

Fig. 2: (a) design of the BIOTA Biodiversity Observatories; (b) characteristics of a plot presumably not subjected to changes during a time span relevant to human beings.

The cells of the General data, which describe the header information on the type, size, location and coordinates of a plot, as well as reference to the first set of digital photos of the plot are shown in Figure 3. Each plot has an identification number, the so-called plot number. Each plot number is unique and serves as a reference in the various tables within the database. The BIOTA Southern Africa Biodiversity Observatories Vegetation Database currently contains approximately 4,000 plot numbers, referring to 1,700 long-term monitoring plots (Biodiversity Observatories) and about 2,300 plots from additional case studies in the vicinity of the Biodiversity Observatories in southwestern Africa.

The description of the broader landscape $\left(25 \mathrm{~km}^{2}\right)$ in which a plot is situated is provided through the service of FAO SOTER (SOTER = Global and National Soil and Terrain Digital Databases of the FAO). The SOTER data are available for many countries and can be down-loaded free of charge from the ISRI webpage (http://www.isric.org/data/data-download).

The plot data of BIOTA Southern Africa is linked through the country ID and the so-called SOTER-unit. In this way, each plot can be described with information as shown in Figure 4.

The medium-scale landscape description refers to geomorphological information that can also be used for stand-alone analysis or customized for user-specific research questions. Typical fields of the geomorphic data set which are part of the landscape description are shown in Figure 3.

The local topography view describes the specific plot. Here the information about the exposition to the sun or the position of the plot relative to the water drainage regime of a slope is of special interest (Fig. 3: local topography). Small icons in the database represent the information on Altitude, Exposition, Inclination and Slope position for the respective plot.

\section{Information about relevés, species and specimens}

On permanent plots of $100 \mathrm{~m}^{2}$ and $1,000 \mathrm{~m}^{2}$ size the species and their composition are recorded at regular intervals by assessing the species name, the projected cover, total height which is stratified into classes $(0-5 \mathrm{~cm}, 5-15 \mathrm{~cm}, 15-50$ cm, 0.5-1 m, 1-2 m, 2-5 m, 5-10 m, > 20 $\mathrm{m}$ ), and the abundance per species (Figs. 5 and 6). In areas where the flora is not well known and identification keys are not readily available, as is the case for several taxa in southern Africa, it is difficult to identify plant species in the field. In such cases, a temporary species name, the so-called field name, is recorded and a reference specimen collected for identification and deposition at a herbarium, e.g. BOL, HBG, KMG, NBG, or WIND. Collected specimens are referred to by a unique collection number. The field name and the collection number always remain unchanged in the database. The specimen can thus be traced back over time, for example, after the process of identification, to the original record.

The relevé record contains general information on the relevé, such as the name of the responsible researcher, a reference to the field book where the field notes are stored and the date when the relevé was conducted. Even relevés void of plant species, as they may occur in deserts or alpine zone of mountains, are recorded. In this case the relevé record would contain no species.

The relevé record is also the place to note properties of the plot at the time of observation, which are not species-related but concern the entire relevé. Examples of such information are the total vegetation cover of the plot or reference to special events like soil or vegetation damages due to a storm or animal activities. Figure 6 gives an overview on the data fields of a relevé.

File numbers and the path to the respective digital photos are also recorded in the database (Fig. 6: relevé record). 


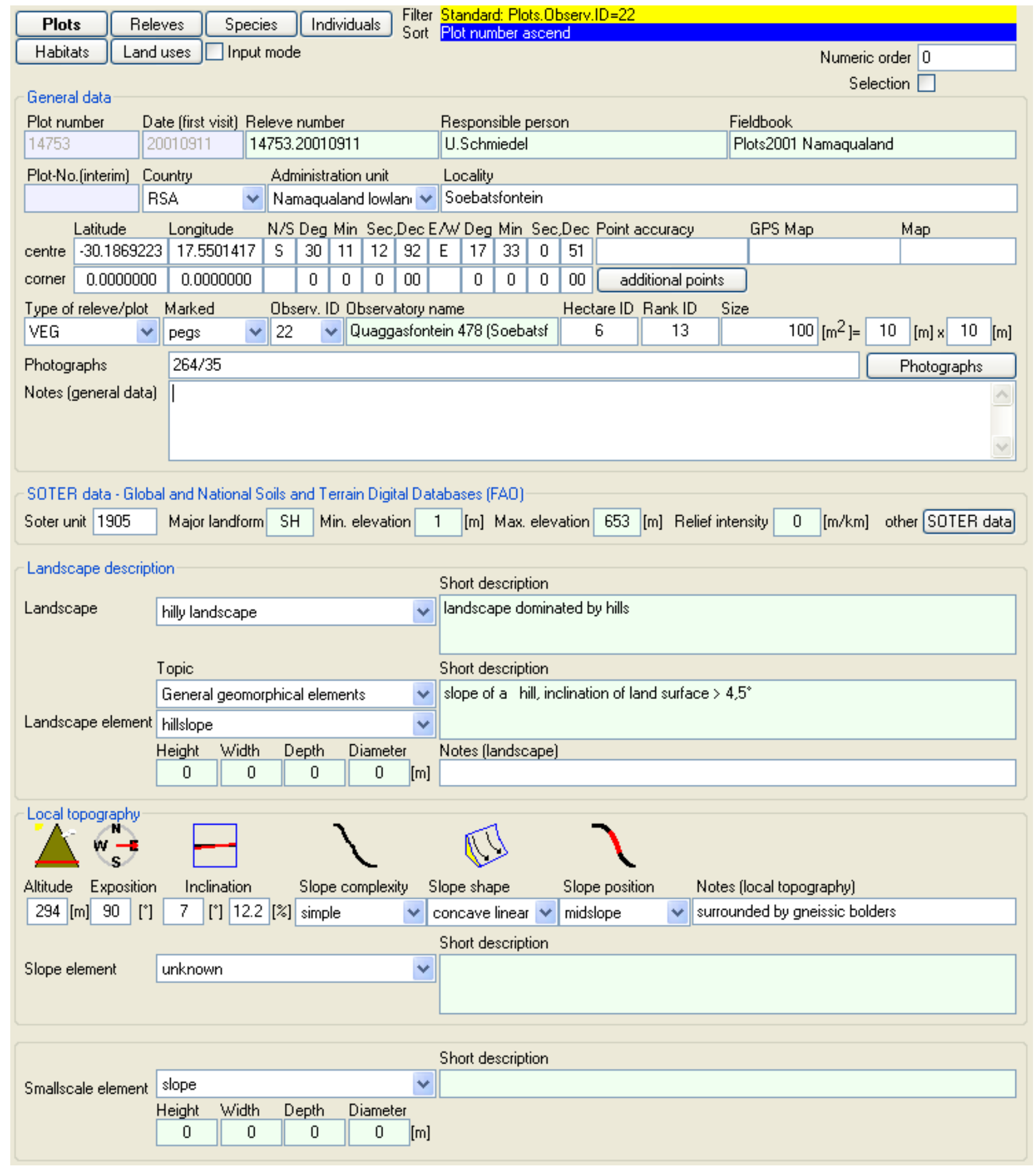

Fig. 3: Table showing the characteristics of a plot that presumably remains unchanged over the time span relevant to human beings. 


\begin{tabular}{|c|c|c|c|}
\hline Minimum elevation & 1 & [m] above sea level & Close \\
\hline Maximum elevation & 653 & [m] above sea level & \\
\hline Slope gradient & - & {$[\%]$} & \\
\hline Relief intensity & - & {$[\mathrm{m} / \mathrm{km}]$} & \\
\hline Major landform & $\mathrm{SH}$ & Medium gradient hill & \\
\hline Regional slope & G & $2-5 \%$ gently undulating & \\
\hline Hyposometry & - & - & \\
\hline Dissection & - & - & \\
\hline General lithology & MA2 & Gneiss, migmatite & \\
\hline Permanent water surface & - & {$[\%]$} & \\
\hline
\end{tabular}

Terrain component number

Proportion [\%]

Dominant slope gradient

Estimated dominant length of slope (metres)

The form of the dominant slope

Characteristic meso-relief or local surface form

Average height (or depth - negative) of the meso-relief in metres

Estimated percentage coverage of the meso-relief elements within the terrain component (Un)consolidated surficial materials which underlie most of the terrain component

Texture of non-consolidated parent material

The average depth to consolidated bedrock in metres

Surface drainage of the terrain component

Depth (metres) of the mean ground water level

Frequency of the natural flooding of the terrain component in classes after FA0 (1990)

Duration of the flooding of the terrain component in classes after FAO (1990)

1 st month during which flooding of the terrain component normally starts

2nd month during which flooding of the terrain component normally starts

3rd month during which flooding of the terrain component normally starts

\begin{tabular}{|c|c|c|}
\hline 1 & \multirow{18}{*}{ Concave } & 2 \\
\hline 80 & & 20 \\
\hline 9 & & 4 \\
\hline 275 & & 350 \\
\hline C & & $\mathrm{V}$ \\
\hline .. & & .. \\
\hline$-\cdot$ & & .- \\
\hline$-\cdot$ & & .. \\
\hline.- & &.$\cdot$ \\
\hline$-\cdot$ & & .. \\
\hline 0.35 & & 0.20 \\
\hline.$\cdot$ & & $\cdot \cdot$ \\
\hline -. & & .- \\
\hline -. & &.$\cdot$ \\
\hline$-\cdot$ & & -. \\
\hline -. & & .. \\
\hline 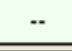 & & .. \\
\hline -. & & -. \\
\hline
\end{tabular}

Fig. 4: SOTER information for landscape characteristics. 


\begin{tabular}{|c|c|c|c|c|c|c|c|c|c|c|c|}
\hline \multicolumn{2}{|c|}{ Plot number } & \multicolumn{2}{|l|}{ Date } & \multicolumn{3}{|c|}{ Releve number } & \multicolumn{3}{|c|}{ Responsible person } & \multicolumn{2}{|c|}{ Fieldbook } \\
\hline \multicolumn{2}{|l|}{14753} & \multicolumn{2}{|c|}{20060815} & \multicolumn{3}{|c|}{14753.20060815} & \multicolumn{3}{|c|}{ U.Schmiedel } & \multicolumn{2}{|c|}{ U.Schmiedel 2006} \\
\hline Name & Stipagro & stis zeyhe & i ssp. z & zeyheri & & & & & & & \\
\hline \multicolumn{12}{|c|}{ Cover $[\%]$} \\
\hline Total & Sum & \multicolumn{4}{|c|}{$0-5 \mathrm{~cm} \quad 5-15 \mathrm{~cm} 15-50 \mathrm{~cm} \quad 0.5-1 \mathrm{~m}$} & $1.2 \mathrm{~m}$ & $2-5 \mathrm{~m}$ & $5-10 m$ & $10-20 \mathrm{~m}$ & $>20 \mathrm{~m}$ & Abundance \\
\hline 0.10 & 0.10 & 0.00 & 0.00 & 0.10 & 0.00 & 0.00 & 0.00 & 0.00 & 0.00 & 0.00 & 1 \\
\hline \multicolumn{2}{|c|}{ Collection number } & \multicolumn{4}{|c|}{ Field name } & & \multicolumn{3}{|c|}{ External collection number } & & \\
\hline 124651 & & Stipa & rostis 5 & Soebatsfon & & & & & & & \\
\hline
\end{tabular}

Fig. 5: Data fields of a species record.

\section{Taxonomic reference data}

African plants have evolved a tremendous diversity of forms and functions in many different habitats. Due to the limited number of published field guides and identification keys, species identifications in certain taxa are still a challenge, especially if large numbers of specimens need to be identified (Muche et al. 2010). Therefore it is very helpful and even a necessity to have an area-specific Taxa Reference List for the study area, which also includes the previously used field names. This Taxa Reference List should allow for changes and additions by the user so that new species can be added and adjustments made of nomenclatural changes. The Taxa Reference List is compiled from literature data, using mostly Germishuizen \& Meyer (2003) and Craven (1999).

The Taxa Reference List ensures consistent and correct spelling of the taxon names when entering the data into the database. Lexicographical information about the taxa (family, life form, growth form, size and texture of leaves, flower colour, flowering time etc.; compare Fig. 7) is also stored in this list. The link between the observations of the plot and the morphological properties of the respective taxa from the database, allows for the analyses of distribution patterns and diversity of various plant traits (e.g. Oldeland et al. 2010, Wesuls et al. 2010).

To get more information about a taxon, the user can link directly to the Photo Guide to Plants of Southern Africa http://www.southernafricanplants.net, to an online version of the Taxa Reference List of BIOTA AFRICA (Muche et al. 2010) or to other Internet sources.

\section{Provision of time series}

Scientific documentation of changes in time is the most important goal for each long-term monitoring project. The database provides a time series of vegetation data from repeated observations which are normally recorded at annual intervals. Technically, the observations are stored in different tables. Records of each single observation per plot are stored in a table, which captures the unique combination of species occurrence, related numerical values (e.g. cover, abundance per species) and the date of observation. The habitat and the land use conditions at the time of observation are stored in other tables. Each relevé is linked to the non-variable plot information (i.e. coordinates, landscape information etc.) in a separate table, while each species record is linked to the taxa specific information (nomenclature, plant functional traits etc.). This allows for many different time series related database queries. For instance, it is possible to ask for species richness or other diversity measures on plots of different sizes, or the changes in the species composition in plots with defined environmental attributes (e.g. altitude, exposition, water drainage, soil type). Another option is to compare groups of species along the time axis. Plant attributes such as life cycle duration, life form or succulence can be used for analyses of changes in species groups over time and space. The combination of multiple observations over many years along a $2,000 \mathrm{~km}$ transect may be a challenge for data management but is invaluable for ecological research.

\section{Data storage and data man- agement}

The vegetation data of the BIOTA Southern Africa Observatories are stored in a MS Access database. A software tool BIOTABase has been developed to manage the input as well as process the complex data. The separating of the storage in MS Access database format on the one hand and an executable data management tool (i.e. BIOTABase) on the other hand has several advantages. BIOTABase, a user friendly interface, guides the researcher through the sometimes complex interrelations between the data entities and the special service functions and this helps avoid typical errors. Such an executable software program does not necessarily depend on a special database product. Therefore, if the requirements of an ongoing project increase the data management software can be adjusted to handle the growing and even more complex database. The use of the database format of MS Access (*.mdb file) is permitted and free of charge under all Windows operating systems. Alternatively, for BIOTABase, one can also use the proprietary software MS Access or a respective freeware as a browser for *.mdb files. The database format is reliable and capable enough to store and handle considerably more than the 400,000 records that are currently stored in the vegetation data of BIOTA Southern Africa (actually up to more than 2 million).

The BIOTABase software can be downloaded free of charge from the BIOTA AFRICA website (http://www.biotaafrica.org/biotabase_ba.php). It allows the use of the original BIOTABase format. The software may also be used to develop new databases, independent of BIOTA AFRICA. 


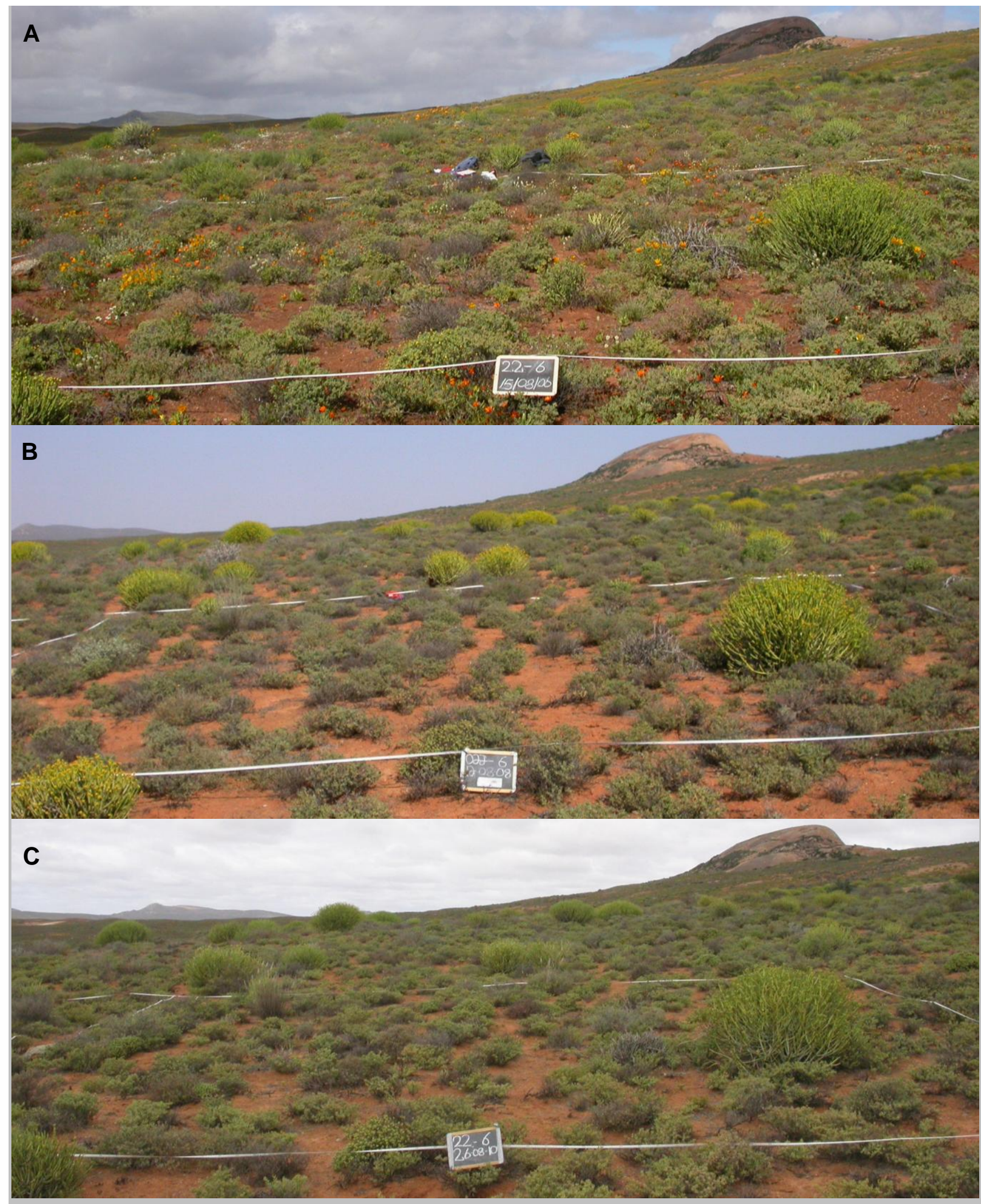

Plate: Vegetation types featured by the vegetation-plot database GIVD AF-00-003.

Time series are a particular strength of this database, here exemplified with the interannual variability in the Ruschio goodiae-Lebeckietum sericeae described by Luther-Mosebach et al. (2012). The photo series depicts plot 14753 of the Biodiversity Observatory \#22, Hectare 06 in the years (A) 2006, (B) 2008 and (C) 2010 (Photos: U. Schmiedel) 


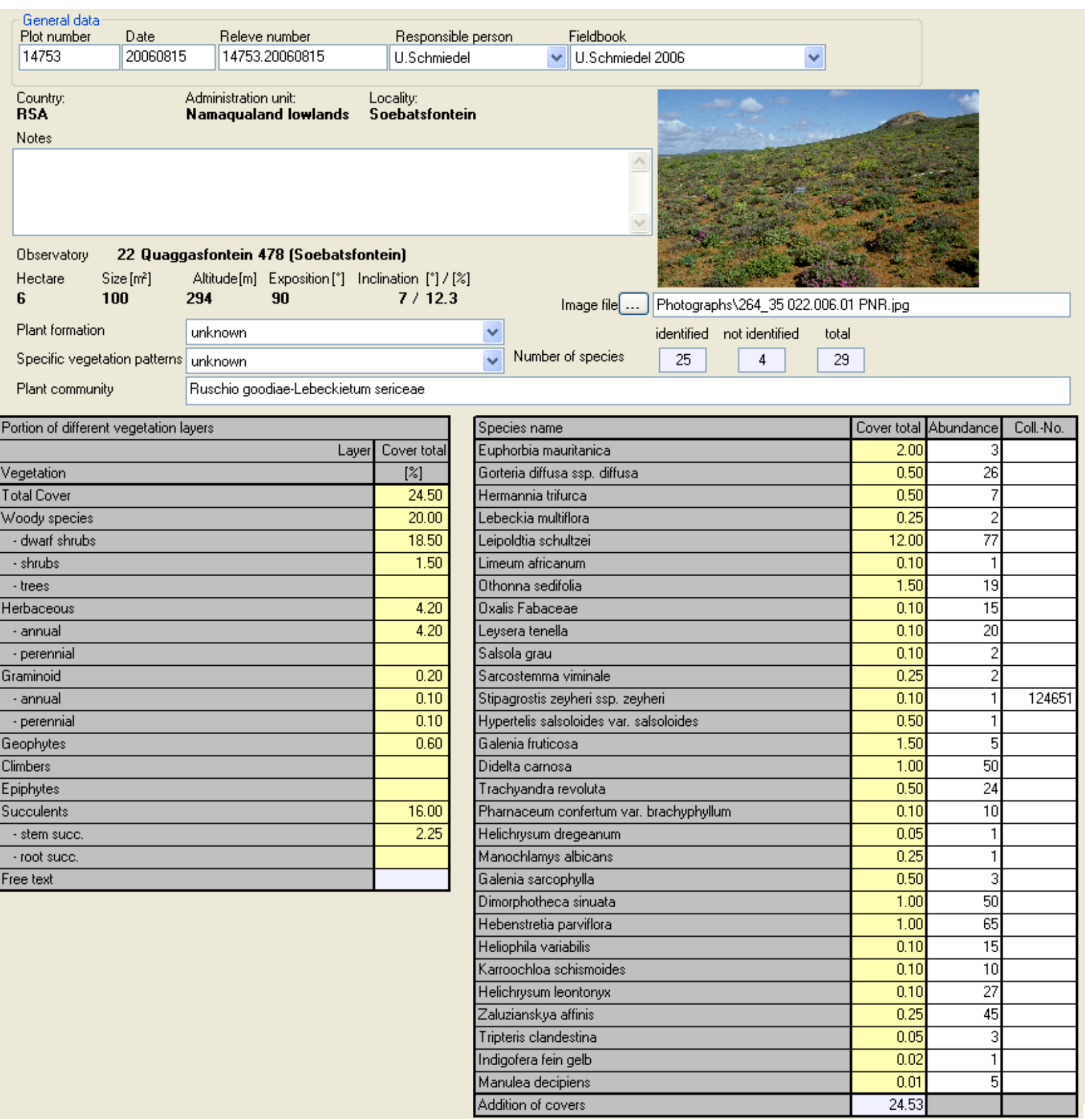

Fig. 6: Data fields of a relevé record.

\section{Some characteristics of the database}

The Fact Sheet and Table 1 give an overview of the available data in the database. The table not only gives information on the availability of data per plots, but also on nested plots and time series. The date of observation has been limited to a specific year because up to now information for all the plots has only been recorded once a year. A special case is the Obser- vatory Kleinberg. Kleinberg is located in the Namib Desert and is by far the most species-poor Observatory of all. The exact GPS-positions were recorded for the few individual plants present in the Observatory and not only at $100-\mathrm{m}^{2}$ or $1,000-\mathrm{m}^{2}$ scale. The last two columns in Table 1 show the number of $100-\mathrm{m}^{2}$ and $1,000-\mathrm{m}^{2}$ plots assessed over the whole nine-year period. In most cases the numbers of monitored plots were consistent over the years. At some of the BIOTA Observato- ries, like at Soebatsfontein (S22) and Goedehoop (S26), several additional plots were recorded as a once off in some of the years. This is an indication of several special research activities that were conducted here and offer additional data beyond the standard procedures. The last row of the table shows the total number of items in the respective column, for example, 772 plots of the size of $100 \mathrm{~m}^{2}$ were observed until 2010. 


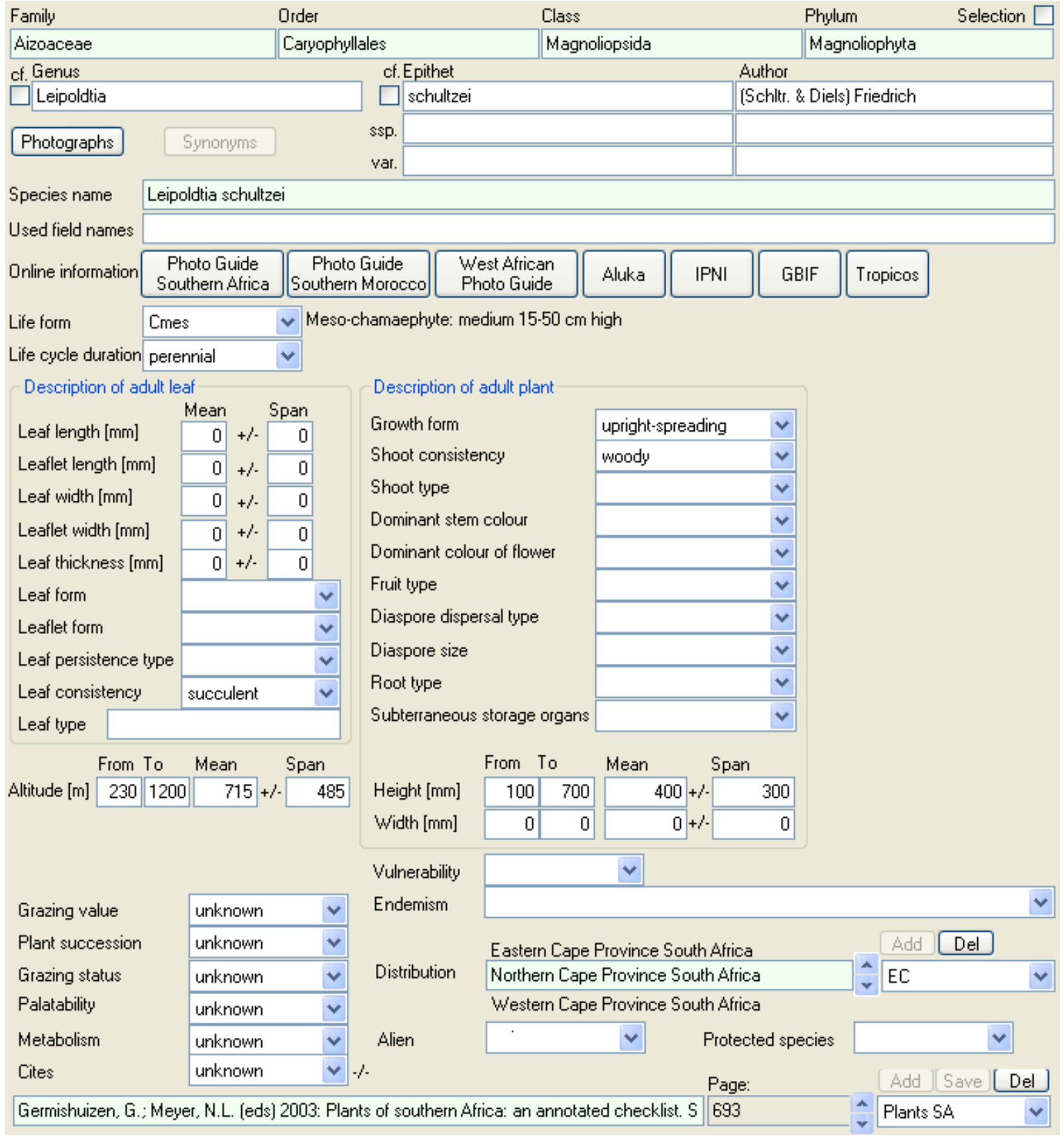

Fig. 7: Data fields of a taxon record.

\section{Conclusions}

The BIOTA Southern Africa Biodiversity Observatories Vegetation Database contains information on patterns of vegetation, plant diversity and their recent changes in south-western Africa. Transect-wide analyses of patterns of vascular plant species, life form composition (Oldeland et al. 2010), vascular plant diversity (Schmiedel et al. 2010) and the relationship to environmental drivers (Mills et al. 2009, Medinski et al. 2010) have already been published. Many more publications based on this vegetation da- tabase in general and the underlying time series in particular are in preparation. The data will also be linked and jointly analysed with large vegetation and diversity data sets from other parts of the continent (especially BIOTA Maroc, BIOTA West, see Jürgens et al. 2012) as well as worldwide. Continuous, standardized long-term monitoring is critical in order to distinguish between the long-term trends in species composition and richness and the inter-annual variability driven by seasonal rainfall patterns and short term land use impacts. This evidence of the plants' response to the various climate change ef- fects is needed in order to provide reliable predictions of future change in vegetation as well as help farmers to adapt to these future conditions. Therefore, the botanical teams at the NBRI Windhoek and at the Biocentre Klein Flottbek of the University of Hamburg have committed themselves to continue the annual monitoring with their own resources. Beyond that, the continuous monitoring of the Biodiversity Observatories will be integrated into upcoming African-German research initiatives. 


\section{Acknowledgements}

BIOTA Southern Africa was sponsored by the German Federal Ministry of Education and Research (BMBF) under promotion numbers 01 LC 0024, 01 LC 0024A, and 01 LC 0624A2. We would like to thank the following BIOTA Southern Africa researchers: Mariam AkhtarSchuster, Renate Austermühle, Niels Dreber, Sophia Etzold, Sabine Greiner, Berit
Hachfeld, Wiebke Hanke, Beate Huss, Lara Hustedt, Fransiska Kangombe, Raphael Kongor, Salomé Kruger, Jona Luther-Mosebach, Carolin Mayer, Markus Müller, Corinna Rickert, Inga U. Röwer, Ben Strohbach, R.C. Turner, Dirk Wesuls, Martin Wittneben, Christina Wolkenhauer. Further, the BIOTA paraecologists Reginald Christiaan, Theodor Cloete, Richard Isaacks, Randall Joseph, Donna Kotze, Gerda Kriel, Marianna Lot,
Robert S. Mukuya, Wynand Pieters are acknowledged for collecting the plant data on the Biodiversity Observatories. Andrzej Suwald conducted large parts of the software programming. We are also greatly indebted to many colleagues at the Biocentre Klein Flottbek, University of Hamburg, for continuous support and critical discussions. We would like to thank Lyn Fish for English editing of the manuscript.

Table 1: Overview of the data currently available in the BIOTA Southern Africa Biodiversity Observatories Vegetation Database. Each row corresponds to a Biodiversity Observatory identified by its number and short name in the first two columns. The next five columns give the number of vascular plant families, genera and species, respectively, as indicators of the plant diversity while the number of perennial and annual species are the first indicators of the species composition. The next columns show the number of plots $\left(100 \mathrm{~m}^{2}\left(10^{2}\right)\right.$ and $1,000 \mathrm{~m}^{2}\left(10^{3}\right)$, respectively) revisited per year. If $100 \mathrm{~m}^{2}$ and $1,000 \mathrm{~m}^{2}$ plots are listed, then the smaller ones are always nested within the larger.

\begin{tabular}{|c|c|c|c|c|c|c|c|c|c|c|c|c|c|c|c|c|c|c|c|c|c|c|c|c|c|c|c|c|}
\hline $\begin{array}{l}\sum_{n} \\
\text { no } \\
\text { On }\end{array}$ & 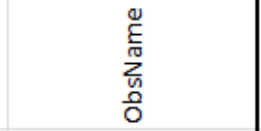 & 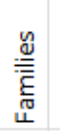 & 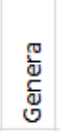 & $\begin{array}{l}\frac{y}{\tilde{N}} \\
\stackrel{\tilde{d}}{n}\end{array}$ & 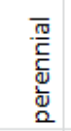 & $\begin{array}{l}\overline{\widetilde{T}} \\
\overrightarrow{\mathrm{C}} \\
\mathrm{c} \\
\mathrm{c}\end{array}$ & & 001 & 200 & & 200 & & 200 & 04 & 200 & & 200 & & 2007 & & 200 & & 2009 & & 201 & & all ye & ears \\
\hline & & & & & & & $10^{2}$ & $10^{3}$ & $10^{2}$ & $10^{3}$ & $10^{2}$ & \begin{tabular}{l|l}
$10^{3}$ & 1 \\
\end{tabular} & $10^{2}$ & $10^{3}$ & $10^{2} 1$ & \begin{tabular}{l|l}
$10^{3}$ & 1
\end{tabular} & $10^{2}$ & $10^{3}$ & $10^{2} 1$ & \begin{tabular}{l|l}
$10^{3}$ & 1
\end{tabular} & $10^{2}$ & $10^{3}$ & $10^{2} 1$ & \begin{tabular}{l|l}
$10^{3}$ & 1
\end{tabular} & $10^{2} 1$ & $10^{3}$ & $10^{2}$ & $10^{3}$ \\
\hline S01 & Mile 46 & 60 & 164 & 322 & 200 & 73 & & 2 & 26 & 27 & & 27 & & & 27 & 27 & & 27 & & 20 & & 28 & & 20 & & & 27 & \\
\hline $\mathrm{S} 02$ & Mutompo & 58 & 169 & 348 & 207 & 82 & & 17 & 27 & 28 & & 24 & & & 27 & 27 & & 27 & & 20 & & 26 & & 20 & & & 28 & 29 \\
\hline S03 & Sonop & 65 & 191 & 385 & 229 & 84 & & 18 & 26 & 29 & 2 & 2 & & & 33 & 33 & & 27 & & & & 33 & & 20 & & & 34 & 34 \\
\hline S04 & Toggery & 50 & 152 & 333 & 155 & 95 & & 20 & 3 & 22 & & 18 & 20 & 20 & 20 & 20 & 20 & 20 & 20 & 20 & 20 & 20 & 20 & 20 & & & 20 & 29 \\
\hline S05 & Otjiamongombe & 53 & 177 & 388 & 185 & 105 & & 21 & 2 & 23 & & 18 & 20 & 20 & 20 & 20 & 20 & 20 & 20 & 20 & 20 & 20 & 20 & 20 & & & 20 & 28 \\
\hline S06 & Okamboro & 49 & 153 & 284 & 130 & 83 & & & & & & & 20 & 20 & 20 & 20 & 10 & 10 & 20 & 20 & 20 & 20 & 20 & 20 & & & 20 & 20 \\
\hline S08 & Niko North & 34 & 92 & 166 & 75 & 36 & 19 & 20 & 19 & 20 & & & 19 & 20 & & & 20 & 20 & 19 & 20 & 20 & 20 & 20 & 20 & & & 20 & 20 \\
\hline S09 & Niko South & 41 & 109 & 204 & 95 & 46 & 17 & 17 & 20 & 20 & & & 20 & 20 & & & 16 & 16 & 19 & 19 & 17 & 17 & 17 & 17 & & & 20 & 20 \\
\hline $\mathrm{S} 10$ & Gellap Ost & 43 & 123 & 264 & 150 & 46 & 14 & 15 & 20 & 20 & 25 & 21 & 20 & 20 & 20 & 20 & 20 & 20 & 20 & 20 & 20 & 20 & 20 & 20 & & & 25 & 21 \\
\hline S11 & Nabaos & 45 & 123 & 230 & 121 & 45 & 15 & 15 & 20 & 20 & 21 & 28 & 20 & 20 & 19 & 20 & 20 & 20 & 20 & 20 & 20 & 20 & 20 & 20 & & & 21 & 28 \\
\hline S12 & Karios & 35 & 84 & 235 & 69 & 26 & 6 & 6 & 1 & 1 & 15 & 16 & 3 & 3 & 15 & 15 & 18 & 17 & 1 & 1 & & & 1 & 1 & & & 26 & 25 \\
\hline S16 & Wlotzkasbaken & 12 & 22 & 41 & 16 & 7 & 22 & 22 & 21 & 21 & 20 & 20 & 2 & 2 & 20 & 20 & & & & & & & & & 21 & 20 & 22 & 22 \\
\hline S17 & Alpha & 30 & 57 & 109 & 48 & 19 & & & 19 & 20 & 18 & 19 & & & 18 & 18 & 18 & 18 & 20 & 20 & & & & & & & 20 & 20 \\
\hline S18 & Koeroegap Vlakte & 35 & 119 & 345 & 137 & 43 & 20 & 20 & 12 & 12 & 1 & 1 & 10 & 10 & 20 & 20 & 14 & 14 & 10 & 10 & & & & & & & 20 & 20 \\
\hline S20 & Numees & 49 & 152 & 610 & 247 & 43 & 14 & 14 & 1 & 1 & 14 & 14 & & & & & 11 & 11 & & & & & & & & & 20 & 20 \\
\hline S21 & Groot Derm & 23 & 66 & 194 & 85 & 34 & 21 & 21 & 19 & 19 & 9 & 9 & 20 & 20 & 20 & 20 & 20 & 20 & & & 1 & 1 & & & & & 21 & 21 \\
\hline S22 & Soebatsfontein & 52 & 183 & 526 & 267 & 87 & 19 & 19 & 49 & 20 & 52 & 20 & 34 & 20 & 34 & 20 & 34 & 20 & 34 & 20 & 34 & 20 & 34 & 20 & 20 & 20 & 81 & 20 \\
\hline S24 & Paulshoek & 54 & 194 & 557 & 308 & 78 & 20 & 20 & 20 & 20 & 20 & 20 & 20 & 20 & 20 & 20 & 19 & 19 & 18 & 19 & 20 & 20 & 20 & 20 & 18 & 18 & 20 & 20 \\
\hline S25 & Remhoogte & 55 & 201 & 562 & 318 & 79 & 20 & 20 & 20 & 20 & 20 & 20 & 20 & 20 & 20 & 20 & 20 & 20 & 20 & 20 & 20 & 20 & 20 & 20 & 20 & 20 & 20 & 20 \\
\hline S26 & Goedehoop & 38 & 127 & 302 & 200 & 52 & 10 & 10 & 20 & 10 & 16 & 10 & 11 & 10 & 12 & 12 & 11 & 11 & 12 & 12 & 12 & 12 & 10 & 10 & 10 & 10 & 29 & 12 \\
\hline S27 & Ratelgat & 42 & 137 & 316 & 205 & 59 & 11 & 11 & 19 & 10 & 14 & 10 & 12 & 11 & 10 & 10 & 10 & 10 & 10 & 10 & 10 & 10 & 10 & 10 & 10 & 10 & 25 & 11 \\
\hline S28 & Moedverloren & 48 & 155 & 429 & 261 & 64 & 20 & 20 & 26 & 20 & 20 & 20 & 20 & 20 & 20 & 20 & 20 & 20 & 20 & 20 & 20 & 20 & 20 & 20 & 20 & 20 & 26 & 20 \\
\hline S29 & Rocherpan & 22 & 36 & 42 & 32 & 5 & & & & & & & & & 4 & & & & & & & 10 & & 20 & & & 4 & 20 \\
\hline S31 & Riverlands & 63 & 207 & 439 & 329 & 50 & & & & & & & & & & & & & & & 10 & & 20 & 20 & & & 20 & 20 \\
\hline S32 & Elandsberg & 62 & 196 & 385 & 269 & 59 & & & & & & & & & & & & & & 20 & & 20 & 20 & 20 & & & 20 & 20 \\
\hline S33 & Cape of Good Hope & 48 & 140 & 287 & 236 & 11 & & & & & & & & & & & & & 20 & 20 & 20 & 20 & 20 & 20 & & & 20 & 20 \\
\hline S34 & Kleinberg & 4 & 4 & 4 & 3 & 1 & & & & & & & & & & & & & & & & & & & & & & \\
\hline \$35 & Gobabeb & 18 & 24 & 37 & 18 & 8 & & & & & & & 8 & 28 & & & 6 & 5 & & & & & 4 & 4 & & & 14 & 31 \\
\hline$\$ 36$ & Ganab & 28 & 44 & 53 & 40 & 8 & & & & & & & & & 4 & 4 & 2 & 2 & & & & & & & 22 & 22 & 22 & 22 \\
\hline S37 & Rooisand & 31 & 69 & 95 & 59 & 26 & & & & & & & & & 21 & 22 & & & & & & & & & & & 21 & 22 \\
\hline S38 & Claratal & 47 & 126 & 205 & 133 & 39 & & & & & & & & & 20 & 20 & & & & 20 & & & & 20 & & & 20 & 20 \\
\hline S39 & Narais & 48 & 136 & 215 & 114 & 62 & & & & & & & 19 & 19 & 20 & 20 & 21 & 21 & 21 & 21 & 21 & 21 & 21 & 21 & & & 21 & 21 \\
\hline$\$ 40$ & Duruchaus & 50 & 134 & 223 & 125 & 47 & & & & & & & 19 & 19 & 20 & 20 & 20 & 20 & 20 & 20 & 20 & 20 & 20 & 20 & & & 20 & 20 \\
\hline S41 & Sandveld & 44 & 108 & 203 & 121 & 49 & & & & & & & & & 20 & 20 & & & & & 21 & 20 & & 20 & & & 21 & 20 \\
\hline S42 & Ogongo & 41 & 96 & 137 & 58 & 47 & & & & & & & & & & & & & & 20 & & 17 & & 20 & & & & 20 \\
\hline$\$ 43$ & Omano go Ndjamba & 37 & 77 & 114 & 42 & 46 & & & & & & & & & & & & & & 20 & & 19 & & & & & & 20 \\
\hline \multirow[t]{2}{*}{$\$ 45$} & Nieuwouldville & & & & & & & & & & & & & & & & & & & & & & & & & & & \\
\hline & all Obs. & & & & 2193 & $508 \sqrt[2]{2}-2$ & 248 & 328 & 3903 & 383 & 2713 & 3213 & 3413 & 346 -5 & 5084 & \begin{tabular}{l|l}
492 &
\end{tabular} & 3744 & 439 & 3484 & \begin{tabular}{l|l}
436 & 3
\end{tabular} & 3504 & \begin{tabular}{l|l}
458 &
\end{tabular} & 3573 & 343 & 43 & 43 & 7727 & 748 \\
\hline
\end{tabular}




\section{References}

Araújo, M.B., Pearson, R.G., Thuiller, W., Erhard, M. (2005): Validation of species-climate impact models under climate change. - Global Change Biology 11: 1504-1513.

Biggs, R., Simons, H., Bakkenes, M., Scholes, R.J., Eickhout, B., van Vuuren, D., Alkemade, R. (2008): Scenarios of biodiversity loss in southern Africa in the 21st century. - Global Environmental Change 18: 296-309. CrossRef

Büdel, B., Darienko, T., Deutschewitz, K. Dojani, S., Friedl, T., Mohr, K., Salisch, M., Reisser, W., Weber, B. (2009): Southern African biological soil crusts are ubiquitous and highly diverse in drylands, being restricted by rainfall frequency. - Microbial Ecology 57: 229247.

Cowling, R.M., Hilton-Taylor, C., Huntley, B.J. (1994): Patterns of plant diversity and endemism in southern Africa: An overview. - In: Huntley, B.J. [Ed.]: Botanical diversity in southern Africa: 3152. Pretoria: National Botanical Institute.

Craven, P. (1999) [Ed.]: A checklist of $\mathrm{Na}$ mibian plant species. -B Southern African Botanical Diversity Network Report

Davis, S.D., Heywood, V.H., Hamilton, A.C. (1994): Centres of plant diversity. A guide and strategy for their conservation. Volume 1. Europe, Africa, South West Asia and the Middle East. Cambridge: WWF and IUCN, IUCN Publications Unit.

Dengler, J., Schmiedel, U., Haarmeyer, D.H., Luther-Mosebach, J., Muche, G (2010): Vascular Plants. - In: Jürgens, N., Haarmeyer, D.H., Luther-Mosebach, J., Dengler, J., Finckh, M., Schmiedel, U. [Eds.]: Biodiversity in southern Africa. Volume 1: Patterns at local scale - the BIOTA Observatories: 32-34. Göttingen: Klaus Hess Publishers.

Germishuizen, G., Meyer, N.L. (2003) [Eds.]: Plants of southern Africa: an annotated checklist. - Strelitzia 14. Pretoria: National Botanical Institute.

Haarmeyer, D.H., Luther-Mosebach, J., Dengler, J., Schmiedel, U., Finckh, M. Berger, K., Deckert, J., Domptail, S.E., Dreber, N., Gibreel, T., Grohmann, C., Gröngröft, A., Haensler, A., Hanke, W. Hoffmann, A., Husted, L.B., Kangombe, F.N., Keil, M., Krug, C.B., Labitzky, T., Linke, T., Mager, D., Mey, W., Muche, G., Naumann, C., Pellowski, M., Powrie, L.W., Pröpper, M., Rutherford, M.C., Schneiderat, U., Strohbach, B.J., Vohland, K., Weber, B., Wesuls, D., Wisch, U., Zedda, L., Büdel, B., Darienko, T., Deutschewitz, K., Dojani, S., Erb, E., Falk, T., Friedl, T., Kanzler, S.-E., Limpricht, C., Linsenmair, K.E., Mohr, K., Oliver, T., Petersen, A., Rambold, G., Zeller, U., Austermühle, R., Bausch, J.,
Bösing, B.M., Classen, N., Dorendorf, J., Dorigo, W., Esler, K.J., Etzold, S., Graiff, A., Grotehusmann, L., Hecht, J., Hoyer, P., Kongor, R.Y., Lang, H., Lieckfeld, L.A.B., Oldeland, J., Peters, J., Röwer, I.U., September, Z.M., Sop, T.K., van Rooyen, M.W., Weber, J., Willer, J., Jürgens, N. (2010): The BIOTA Observatories. - In: Jürgens, N., Haarmeyer, D.H., Luther-Mosebach, J., Dengler, J., Finckh, M., Schmiedel, U. [Eds.]: Biodiversity in southern Africa. Volume 1: Patterns at local scale - the BIOTA Observatories: 6-801. Göttingen: Klaus Hess Publishers.

Hoffman, M.T., Ashwell, A. (2001): Nature divided - land degradation in South Africa. - Cape Town: UCT Press.

Huntley, B. (1989): Biotic diversity in southern Africa. concepts and conservation. - Cape Town: Oxford Uni-versity Press.

Jürgens, N. (1997): Floristic biodiversity and history of African arid regions. Biodiversity and Conservation 6: 495-514. CrossRef

Jürgens, N., Schmiedel, U., Hoffman, M.T. (2010a): Challenges and international framework. - In: Jürgens, N., Haarmeyer, D.H., Luther-Mosebach, J., Dengler, J., Finckh, M., Schmiedel, U. [Eds.]: Biodiversity in southern Africa. Volume 1: Patterns at local scale - the BIOTA Observatories: 1-1. Göttingen: Klaus Hess Publishers.

Jürgens, N., Schmiedel, U., Gröngröft, A., Petersen, A., Finckh, M., Haarmeyer, D.H., Dengler, J. (2010b): Spatial design of the BIOTA Biodiversity Observatories. - In: Jürgens, N., Haarmeyer, D.H., Luther-Mosebach, J., Dengler, J., Finckh, M., Schmiedel, U. [Eds.]: Biodiversity in southern Africa. Volume 1: Patterns at local scale - the BIOTA Observatories: 12-13. Göttingen: Klaus Hess Publishers.

Jürgens, N., Schmiedel, U., Haarmeyer, D.H., Dengler, J., Finckh, M., Goetze, D., Gröngröft, A., Hahn, K., Koulibaly, A., Luther-Mosebach, J., Muche, G., Oldeland, J., Petersen, A., Porembski, S., Rutherford, M.C., Schmidt, M., Sinsin, B., Strohbach, B.J., Thiombiano, A., Wittig, R., Zizka, G. (2012): The BIOTA Biodiversity Observatories in Africa - A standardized framework for large-scale environmental monitoring. - Enviromental Monitoring and Assessment 184: 655-678.

Klak, C., Reeves, G., Hedderson, T. (2004): Unmatched tempo of evolution in Southern African semi-desert ice plants. - Nature 427: 63-65. CrossRef

Krug, C.B., Esler, K.J., Hoffman, M.T., Henschel, J., Schmiedel, U., Jürgens, N. (2006): North-South cooperation through BIOTA: an interdisciplinary monitoring programme in arid and semi-arid southern Africa. - South African Journal of Science 102: 187-190.
Linder, H.P. (2003): The radiation of the Cape flora, southern Africa. - Biological Reviews 78: 597-638. CrossRef

Luther-Mosebach, J., Dengler, J., Schmiedel, U., Röwer, I.U., Labitzky, T., Gröngröft, A. (2012): A first formal classification of Hardeveld vegetation in Namaqualand, South Africa. - Applied Vegetation Science 15: 401-431. CrossRef

McClean, C.J., Doswald, N., Küper, W., Sommer, J.H., Barnard, P., Lovett, J.C. (2006): Potential impacts of climate change on sub-Saharan African plant priority area selection. - Diversity and Distribution 12: 645-655. CrossRef

Medinski, T.V., Mills, A.J., Esler, K.J., Schmiedel, U., Jürgens, N. (2010): Do soil properties constrain species richness? Insights from boundary line analysis across several biomes in south western Africa. - Journal of Arid Environments 74: 1052-1060. CrossRef

Mendelsohn, J., Jarvis, A., Roberts, C. Robertson, T. (2002): Atlas of Namibia: a portrait of the land and its people. Cape Town: Davis Philip Publishers.

Midgley, G.F., Thuiller, W. (2007): Potential vulnerability of Namaqualand plant diversity to anthropogenic climate change. - Journal of Arid Environments 70: 615-628. CrossRef

Myers, N., Mittermeier, R.A., Mittermeier, C.G., de Fonseca, G.A.B., Kent, J. (2000): Biodiversity hotspots for conservation priorities. - Nature 403: 853-858. CrossRef

Muche, G., Hillmann, T., Suwald, A., Jürgens, N. (2010): Data access and availability: BIOTA Data Facility. - In: Schmiedel, U., Jürgens, N. [Eds.]: Biodiversity in southern Africa. Volume 2: Patterns and processes at regional scale: 337-342. Göttingen: Klaus Hess Publishers.

Mucina, L., Rutherford, M.C. (2006) [Eds.]: The vegetation of South Africa, Lesotho and Swaziland. - Strehlitzia 19: 1-807 Pretoria: South African National Biodiversity Institute.

Musil, C.F., Van Heerden, P.D.R., Cilliers, C.D., Schmiedel, U. (2009): Mild experimental climate warming induces metabolic impairment and massive mortalities in southern African quartz field succulents. - Environmental and Experimental Botany 66: 79-87. CrossRef

Peters, J. (2010): Plant diversity patterns at different spatial scales in a semi-arid savanna ecosystem in central Namibia - Diplom thesis, University of Greifswald. URL: http://www.biologie.unihamburg.de/bzt/syst/Diplom_thesis_Jan Peters_2009.pdf.

Petersen, A. (2008): Pedodiversity of southern African drylands. - Hamburger Bodenkundliche Arbeiten 62. URL: http://www.sub.uni-hamburg.de/opus/ volltexte/2008/3728/. 
Petersen, A., Gröngröft, A., Mills, A., Miehlich, G. (2010): Soils along the BIOTA transects. - In: Schmiedel, U., Jürgens, N. [Eds.]: Biodiversity in southern Africa. Volume 2: Patterns and processes at regional scale: 84-92. Göttingen: Klaus Hess Publishers.

Schmiedel, U., Jürgens, N. (2005): Biodiversity Observatories. A new standardised monitoring tool for biodiversity studies. - Basic and Applied Dryland Research 1: 87-91.

Schmiedel, U., Jürgens, N., Oldeland, J., Dengler, J., Luther-Mosebach, J., Haarmeyer, D.H., Finckh, M. (2010a): The BIOTA transects in southern Africa. - In: Jürgens, N., Haarmeyer, D.H., LutherMosebach, J., Dengler, J., Finckh, M., Schmiedel, U. [Eds.]: Biodiversity in southern Africa. Volume 1: Patterns at local scale - the BIOTA Observatories: 7-11. Göttingen: Klaus Hess Publishers.

Schmiedel, U., Dengler, J., LutherMosebach, J., Gröngröft, A., Muche, G., Petersen, A., Strohbach, B.J., Jürgens, N. (2010b): Patterns and dynamics of vascular plant diversity along the BIOTA transects in southern Africa. - In:
Schmiedel, U., Jürgens, N. [Eds.]: Biodiversity in southern Africa. Volume 2: Patterns and processes at regional scale: 118-135. Göttingen: Klaus Hess Publishers.

Scholes, R.J., Mace, G.M., Turner, W., Geller, G.N., Jürgens, N., Larigaudrie, A., Muchoney, D., Walther, B.A. Mooney, H.A. (2008): Toward a global biodiversity observing system. - Science 321: 1044-1045. CrossRef

Sommer. J.H., Kreft, H., Kier, G., Jetz, W. Mutke, J., Barthlott, W. (2010): Projected impacts of climate change on regional capacities for global plant species richness. - Proceedings of the Royal Society London, B 277: 2271-2280. Cross$\underline{\text { Ref }}$

Thuiller, W., Midgley, G.F., Hughes, G.O., Bomhard, B., Drew, G., Rutherford, M.C., Woodward, F.I. (2006): Endemic species and ecosystem sensitivity to climate change in Namibia. - Global Change Biology 12: 759-776. CrossRef

Thomas, C.D., Cameron, A., Green, R.E., Bakkenes, M., Beaumont, L.J., Collingham, Y.C., Erasmus, B.F.N., Siqueira, M.F. de, Grainger, A., Hannah, L.,
Hughes, L., Huntley, B., Jaarsveld, A.S. van, Midgley, G.F., Miles, L., OrtegaHuerta, M.A., Townsend Peterson, A., Phillips, O.L., Williams, S.E. (2004): Extinction risk from climate change. - Nature 427: 145-148. CrossRef

van Vuuren, D.P., Sala, O.E., Pereira, H.M. (2006): The future of vascular plant diversity under four global scenarios. Ecology \& Society 11(2): Article 25, URL: http://www.ecologyandsociety.org/ vol11/iss2/art25/.

Gerhard Muche* (gerhard.muche@unihamburg.de), Ute Schmiedel (ute.schmiedel@uni-hamburg.de) \& Norbert Jürgens (norbert.juergens@t-online.de)

Biodiversity, Evolution and Ecology of Plants, Biocentre Klein Flottbek \& Botanical Garden, University of Hamburg Ohnhorststr. 18

22609 Hamburg, GERMANY

*Corresponding author 
